\title{
Desenvolvimento local, turismo e populações tradicionais: elementos conceituais e apontamentos para reflexão
}

\author{
Local development, tourism and traditional populations: conceptual elements \\ and notes for reflection
}

\section{Développement local, du tourisme et les populations traditionnelles: élements conceptuels et des notes de réflexion}

\section{Desarrollo local, turismo y poblaciones tradicionales: elementos conceptuales y notas para la reflexión}

\author{
Wilson Alves de Araújo ${ }^{1}$ \\ Joelma Abrantes Guedes Temoteo ${ }^{2}$ \\ Maristela Oliveira de Andrade ${ }^{2}$ \\ Salvador Dal Pozzo Trevizan ${ }^{3}$
}

Recebido em 23/09/2016; revisado e aprovado em 15/04/2017; aceito em 23/05/2017

DOI: http://dx.doi.org/10.20435/inter.v18i4.1392

\begin{abstract}
Resumo: O Objetivo deste artigo foi ampliar a discussão sobre a relação entre os conceitos de desenvolvimento local, turismo e populações tradicionais. Trata-se de uma pesquisa de revisão narrativa e bibliográfica, tendo como base a atividade turística e sua relação com as comunidades indígenas do Brasil, especificamente dos Pataxó no sul da Bahia e os Potiguara, na Paraíba. Considera-se que o turismo, se bem planejado, pode gerar impactos positivos, como a afirmação da identidade cultural das comunidades indígenas.
\end{abstract}

Palavras-chave: turismo cultural; etnoturismo; comunidades indígenas; cultura; sustentabilidade ambiental.

Abstract: The objective of this paper was to broaden the discussion on the relationship between local development concepts, tourism and traditional communities. It is a research of narrative and bibliographical revision, based on tourist activity and its relationship with indigenous communities in Brazil, specifically the Pataxó in southern Bahia and Potiguara, Paraiba. It is considered that tourism is well planned can generate positive impacts, such as the affirmation of the cultural identity of indigenous communities.

Key words: cultural tourism; ethnoturism; indigenous communities; culture; environmental sustainability. Résumé : L'objectif de cet article était d'élargir le débat sur la relation entre les concepts de développement local, le tourisme et les communautés traditionnelles. II est une revue de la littérature narrative et de la recherché, basée sur le tourisme et ses relations avec les communautés autochtones au Brésil, en particulier de la Pataxó à Bahia et Potiguara, Paraiba. Il est considéré que le tourisme est bien planifié peut générer des impacts positifs, tels que l'affirmation de l'identité culturelle des communautés autochtones.

Mots-clés: tourisme culturel; etnoturismo; les communautes autochtones; culture; durabilite environnementale.

Resumen: El objetivo de este trabajo fue ampliar la discusión sobre la relación entre los conceptos de desarrollo local, el turismo y las comunidades tradicionales. Se trata de una investigación de revisión narrativa y bibliográfica, con base en la actividad turística y su relación con las comunidades indígenas en Brasil, específicamente de los Pataxó en el sur de Bahia y Potiguara, Paraiba. Se considera que el turismo está bien planificado puede generar impactos positivos, como la afirmación de la identidad cultural de las comunidades indígenas.

Palabras clave: turismo cultural; etnoturismo; comunidades indígenas; cultura; sostenibilidad ambiental.

\footnotetext{
${ }^{1}$ Universidade do Estado da Bahia (UNEB), Eunápolis, Bahia, Brasil.

${ }^{2}$ Universidade Federal da Paraíba (UFPB), João Pessoa, Paraíba, Brasil.

${ }^{3}$ Universidade Estadual de Santa Cruz (UESC), Ilhéus, Bahia, Brasil.
} 


\section{INTRODUÇÃO}

O objetivo deste trabalho é ampliar a discussão sobre a relação entre os conceitos de desenvolvimento local, turismo e populações tradicionais e suas aplicações. Especificamente, pretende-se discutir em que consiste o desenvolvimento local sustentável; estabelecer parâmetros de como o turismo pode contribuir para esse desenvolvimento; e indicar as relações que podem existir entre turismo, desenvolvimento local sustentável e desenvolvimento de comunidades tradicionais, especificamente, comunidades indígenas.

Dessa forma, considera-se o desenvolvimento como um processo que pressupõe transformações nas relações econômicas e sociais de comunidades. Se, no passado recente, esse termo foi utilizado como sinônimo de crescimento econômico, ao desenvolvimento que se tem atribuído o complemento de "local", este se relaciona com a capacidade de exigir e promover transformações que contemplem os indivíduos dessas comunidades de maneira participativa e sustentável.

Sabe-se que é peculiar à atividade turística uma relação com o ambiente natural, com as comunidades e suas culturas, pois os utiliza como recurso primário e fator de atração de seus visitantes, ao mesmo tempo, que não é raro impactá-los negativamente. Dessa forma, o turismo também se apropria das culturas e comunidades locais e interfere necessariamente no desenvolvimento local.

Nas últimas duas décadas, o conceito de desenvolvimento local tem sido apontado como uma nova proposta de desenvolvimento para questões relativas à compatibilidade entre ambiente, comunidades e sustentabilidade (KASHIMOTO; MARINHO; RUSSEFF, 2002; MARTINS, 2002; ARNAUDO; CORBELLA, 2013). Assim, uma das atividades econômicas que se têm estudado como aplicáveis nesse novo modelo de desenvolvimento é a do turismo, quando se aponta o turismo sustentável como uma alternativa viável, economicamente capaz de diminuir os impactos ambientais e sociais acelerados com o seu incremento.

A metodologia utilizada nesta pesquisa, bem como o método de investigação, possibilita a sua classificação como uma pesquisa de revisão narrativa e bibliográfica (VERGARA 2003; SARAIVA, 2007). No aspecto bibliográfico, foi realizada revisão da literatura, tomando-se como suporte de informação uma revisão de trabalhos publicados sobre a base conceitual, destacando-se a atividade turística e sua relação com as comunidades indígenas do Brasil, especificamente dos Pataxó no sul da Bahia e os Potiguara, na Paraíba. A escolha dessas populações tradicionais foi considerada pela especificidade de serem os únicos povos indígenas que vivem na região costeira do nordeste brasileiro, em áreas consideradas destinos turísticos de sol e praia.

\section{DESENVOLVIMENTO LOCAL: PERSPECTIVAS PARA A SUSTENTABILIDADE}

Desenvolvimento, em termos conceituais, pode ser descrito observando-se duas linhas de pensamento econômico. Uma, de natureza teórica, considera desenvolvimento como sinônimo de crescimento econômico, e, outra, voltada mais para a realidade empírica, considera imprescindível adicionar ao crescimento indicadores que possam refletir melhorias nas condições de vida das pessoas, tais como: saúde, educação, segurança e qualidade ambiental. Dessa maneira, o crescimento se reflete no progresso das sociedades como um todo, não somente no aspecto econômico, mas em suas múltiplas dimensões (MARTINELLI; JOYAL, 2004; SOUZA, 2005; ARAÚJO, 2010). 
De acordo com Sen (2010, p. 28), “[...] Uma concepção adequada de desenvolvimento deve ir muito além da acumulação de riqueza e do crescimento do Produto Nacional Bruto e de outras varáveis relacionadas à renda". Há um reconhecimento generalizado de que a premissa do desenvolvimento é melhorar a qualidade de vida e o bem-estar social dos indivíduos e das comunidades. Ele não incide sobre um conjunto vazio. O desenvolvimento ocorre em uma determinada comunidade, em um território específico, sendo evidente a natureza territorial do desenvolvimento. O desenvolvimento local passa a ser uma alternativa para as comunidades locais assumirem o papel de protagonistas desse processo (CASTILHO; ARENHARDT; BOURLEGAT, 2009; FARIA, 2012; MARTíNEZ; VILLA; VÁZQUEZ, 2013).

Nas últimas décadas, os termos "desenvolvimento Local" e "sustentabilidade" se tornaram recorrentes, e as discussões em torno de ambos têm sido acirradas pela amplitude dos conceitos, apropriações inadequadas e distorcidas em relação aos sentidos sugeridos pelos pesquisadores desses temas.

Pensar o desenvolvimento local, de acordo com Martins (2002, p. 51), é "dotá-lo de um caráter mais humano", partindo do pressuposto de que as pessoas da comunidade local devem participar "ativamente e não apenas serem beneficiárias do desenvolvimento". Esse seria, de acordo com esse autor, o principal diferencial do desenvolvimento local. Para tanto, configura-se como indispensável uma mudança de postura, questionando-se inclusive concepções e crenças teóricas, constituindo-se em um dos principais desafios nesse processo, pois requer uma visão de mundo bem distinta da convencional.

Faz-se relevante destacar que o termo "participação comunitária" também precisa ser compreendido de maneira mais ampla e não deve ser reduzido a "envolvimentos esporádicos e parciais de alguns órgãos e instituições de representação social". Ao invés disso, a participação deve ser entendida como um "empenho pessoal por um aprendizado difícil das regras e meios de se fazer ouvir, entender e atender" (MARTINS, 2002, p. 54).

A mudança conceitual necessária do desenvolvimento local implica revestir o conceito em um processo de transformação social, econômico, cultural e político das pessoas, individualmente, e de uma sociedade, apoiando-se na valorização dos indivíduos em sua plenitude, culminando com a melhoria de vida da comunidade local.

Nesse caso, a qualidade de vida da comunidade deve ser prioritariamente considerada, superando-se os problemas básicos como acesso à educação, saúde, saneamento básico, energia, entre outros, para o efetivo alcance do desenvolvimento local. Não obstante, devem ser considerados, também, como os indivíduos inter-relacionam-se na vida cotidiana, pois esta é a base para se construir a sua identidade sobre uma base territorial (CASTILHO; ARENHARDT; BOURLEGAT, 2009).

A construção da identidade também deve ser incorporada como parte importante no processo de construção de um desenvolvimento local, "imprescindível ao fortalecimento da comunidade em seu ambiente, possibilitando-Ihe a escolha das melhores soluções e, consequentemente, a condução do processo de desenvolvimento local" (KASHIMOTO; MARINHO; RUSSEFF, 2002, p. 41). Nesse mesmo trabalho, os autores também tratam da importância desse processo de valorização da identidade local relacionando-o à atividade do turismo e à sustentabilidade de uma comunidade. Afirmam que os impactos do turismo em culturas locais podem ser acentuados, pois a própria atividade gera o aumento da densidade populacional e a seletividade na oferta de trabalho nas comunidades onde o turismo se instala como alternativa de desenvolvimento. 
De fato, a inserção do turismo tem ocasionado a substituição das atividades tradicionais, como no caso de pescadores artesanais, cujos filhos abandonam o trabalho dos pais e se tornam assalariados nos meios de hospedagem (ESPÍNOLA; ANDRADE 2015), e de pequenos agricultores que se desinteressam pelo duro trabalho nas roças para serem guias de trilhas ecológicas (LOZADA, 2017).

Nesse sentido, é de se esperar que a dinâmica da atividade turística impacte tanto positiva quanto negativamente a sustentabilidade ambiental de uma comunidade. Entretanto o fortalecimento da identidade de uma comunidade faz-se imprescindível tanto como premissa do desenvolvimento local, como para a sua sustentabilidade, importando aos indivíduos dessa comunidade se reconhecerem e "assumirem esse eficaz instrumento com o objetivo de se tornar protagonista do seu próprio processo de desenvolvimento local" (KASHIMOTO; MARINHO; RUSSEFF, 2002, p. 39). Bacal e Miranda (1997) acrescentam que a dinamização da atividade turística chega a desafiar inclusive a sustentabilidade dos recursos naturais, bem como a valorização da identidade local.

Corroborando com essa ideia e agrupando os conceitos de desenvolvimento local, fortalecimento da identidade de uma comunidade e sustentabilidade, atualmente, de acordo com Arnaudo e Corbella (2013, p. 4), "[...]. dentro da corrente de pensamento que defende o desenvolvimento endógeno ou local considera-se que o desenvolvimento não vem de uma única fonte ou ocorre da mesma forma em diferentes lugares". Nas comunidades que possuem uma singularidade cultural e territorial muito proeminente, o desenvolvimento pode manifestar-se a partir de caminhos próprios e produtos específicos e exclusivos de seu território.

Considera-se, conforme assevera Dias (2008, p. 87), que “[...] o turismo tem um potencial de criar efeitos benéficos no meio ambiente, contribuindo para a proteção ambiental e a conservação". É, também, segundo o mesmo autor, uma alternativa para o crescimento da consciência dos valores ambientais. Assim, as comunidades locais podem lançar mão dessa atividade, como opção ao desenvolvimento local, promovendo a sustentabilidade de suas comunidades.

Dessa forma, na próxima seção, apresentam-se os desafios e as oportunidades do turismo sustentável para as localidades, pontuando-se a atividade turística como fenômeno social, moderno e impactante: tanto do ponto de vista negativo quanto nos seus aspectos positivos.

\section{TURISMO SUSTENTÁVEL: DESAFIOS E OPORTUNIDADES}

O turismo, como atividade moderna, é tradicionalmente considerado como fenômeno social. Entretanto, em razão do número de indivíduos que estão direta e indiretamente relacionados com esse fenômeno, o turismo passa a ter dimensões socioeconômicas evidentes. Assim, a atividade turística engloba uma grande proporção de pessoas para desempenhar as mais diversas funções que essa atividade pode beneficiar. Segundo a Organização Mundial do Turismo (OMT, 2014, p. 3), "O turismo compreende as atividades que realizam as pessoas durante suas viagens e estadas em lugares diferentes ao seu entorno habitual, por um período consecutivo inferior a um ano, com a finalidade de lazer, negócio ou outras". Ele é um dos setores com os maiores e mais rápidos crescimentos econômicos do mundo, representando: $5 \%$ do PIB global; 235 milhões de empregos em todo o mundo; 1,8 bilhão de turistas internacionais esperados em 2030; e US\$1,03 bilhões de divisas gerados pelos turistas. 


\section{De acordo com Coriolano (2003, p. 38) o turismo}

[...] é uma das mais novas modalidades do processo de acumulação, que vem produzindo novas configurações geográficas e materializando o espaço de forma contraditória, pela ação do Estado, das empresas, dos residentes, e dos turistas. [...] O turismo, para se reproduzir, segue a lógica do capitalismo, quando poucos se apropriam dos espaços e dos recursos neles contidos apresentando-os como atrativos transformados em mercadorias.

Essa lógica de apropriação dos espaços por poucos indivíduos que passam a explorá-los como atrativos apresenta uma tendência à geração de impactos ambientais, econômicos e sociais negativos e que podem fazer com que a atividade turística assim desenvolvida se torne insustentável a médio e longo prazo. Nesse sentido, Lage e Milone (2001, p. 135) sustentam que "[...] Em muitas situações, as atividades turísticas impõem certos custos sociais e ambientais às regiões turísticas e aos residentes".

Devido aos impactos negativos do turismo, tem-se questionado frequentemente as potencialidades reais do turismo como uma ferramenta para o desenvolvimento e como um meio de maximizar o bem-estar da população nativa (SWARBROOKE, 2000; ARCHER; COOPER, 2002; CORIOLANO, 2003). Entende-se, pois, que a qualidade de vida da comunidade esteja implícita no conceito de desenvolvimento local.

Acredita-se que a atividade turística, quando bem planejada, pode auxiliar na minimização dos problemas ambientais e sociais decorrentes da atividade, gerando impactos econômicos positivos. A esse turismo bem planejado, responsável com as populações receptoras e preocupado com a diminuição dos impactos potenciais da atividade, atribui-se o nome de Turismo Sustentável (DIAS, 2008; BRASIL, 2010).

O turismo sustentável tem sido defendido como um segmento que busca exatamente o equilíbrio dos ecossistemas naturais atrelados à sustentabilidade local, onde o visitante, aberto para novas experiências, capta a identidade do lugar visitado, respeitando seus costumes, valores e suas crenças.

Vale ressaltar a importância desse respeito às culturas locais e o fortalecimento da identidade da comunidade, concomitantemente ao planejamento do turismo, que se acredita fluir através da ativa participação dos atores comunitários no processo de desenvolvimento da atividade turística. Um turismo que aconteça sem o cuidado com tais questões tende a gerar desequilíbrios e impactos, tornando-se insustentável social e culturalmente.

Assim, como se pode perceber, o conceito de turismo sustentável está em total consonância com as bases do conceito de sustentabilidade. No documento sobre Turismo e Sustentabilidade do Ministério do Turismo (Mtur), pode-se observar que para a OMT,

[...] o desenvolvimento sustentável do turismo é um processo contínuo que requer monitoramento constante dos impactos que a atividade pode causar, de modo que, com ações de manejo, seja possível minimizar os impactos negativos e maximizar os benefícios potenciais, introduzindo medidas preventivas ou de correção de rumos (BRASIL, 2007a, p. 18).

O mesmo documento ressalta ainda que esse processo exige a participação e o comprometimento de todos os atores envolvidos com o turismo, como o poder público, os empresários, a população residente e os próprios turistas. E conclui afirmando que "produtos turísticos sustentáveis são desenvolvidos em harmonia com o meio ambiente e culturas locais, de forma que estes se convertam em permanentes beneficiários, e não meros expectadores do processo" (BRASIL, 2007a, p. 18). Essa abordagem, como argumenta Swarbrooke (2000), coloca-se em 
contraposição à equivocada ideia de que o turismo sustentável seja apenas uma modalidade de atividade turística do turismo de massa, mesmo tratando-se de um conceito mal definido, sujeito a inúmeras interpretações.

Avanços na tentativa de delimitar as bases do turismo sustentável já são observados. No Brasil, o Conselho Brasileiro para o Turismo Sustentável (CBTS) definiu, no âmbito do Programa de Certificação do Turismo Sustentável (PCTS), coordenado pelo Instituto de Hospitalidade (IH), sete princípios básicos para se permitir a distinção entre o que seria sustentável e não sustentável na atividade turística. Assim, só poderá ser considerado sustentável o turismo que estiver de acordo com os seguintes princípios: (i) respeitar a legislação vigente; (ii) garantir os direitos das populações locais; (iii) conservar o meio ambiente natural e sua diversidade; (iv) considerar o patrimônio cultural e valores locais; (v) estimular o desenvolvimento social e econômico dos destinos turísticos; (vi) garantir a qualidade dos produtos, processos e atitudes; e (vii) estabelecer o planejamento e a gestão responsáveis (IH, 2005).

O desafio em alcançar o desenvolvimento sustentável em destinos turísticos exige uma série de medidas vigorosas baseadas em trocas complexas, visto ser necessário conciliar os diversos interesses individuais dos envolvidos, que buscam maximizar seus benefícios pelo seu ponto de vista individual (BIGNÉ; FONT; ANDREU, 2000).

Entre essas medidas, se seguidos os princípios mencionados pelo CBTS, acredita-se que o turismo sustentável poderá gerar oportunidades, contribuindo de maneira positiva para a redefinição da realidade de comunidades receptoras, incluindo-as em um processo de desenvolvimento local que valorize a participação de seus residentes na preservação ambiental e, também, nos aspectos econômicos e socioculturais locais. Resultando no fortalecimento ainda da identidade local das comunidades.

\section{DAS POPULAÇÕES TRADICIONAIS ÀS COMUNIDADES LOCAIS: SÍNTESE E REFLEXÃO}

Desde a década de 1980, vem se tornando evidente a mudança de paradigmas em torno do conceito de desenvolvimento, especialmente, a partir do surgimento da teoria do desenvolvimento local. Nesse caso, a ênfase recai sobre a (re)valorização da economia e das potencialidades locais que viabilizam as características culturais, naturais e sociais da localidade. Observa-se um entendimento generalizado de que, para se obter êxito no desenvolvimento local, é necessário que o território tenha uma estratégia própria que lhe permita alcançar uma dinâmica econômica, social e ambiental sustentável. Possibilita, dessa forma, as transformações dos atores locais em agentes do desenvolvimento, entendidos como tais os indivíduos residentes e as instituições capazes de desenvolver e gerenciar propostas que permitam tornar realidade as potencialidades locais (KASHIMOTO, MARINHO; RUSSEFF, 2002; CASTILHO, ARENHARDT; BOURLEGAT, 2009; ARNAUDO; CORBELLA, 2013).

Considerando-se que uma boa organização comunitária seja imprescindível para o desenvolvimento local, nesta seção, levam-se em conta os conceitos de cultura, identidade, territorialidade. Para tanto, as concepções sobre sociedade, comunidades locais e tradicionais serão tratadas à luz do desenvolvimento local.

Quanto à cultura, trata-se de um conceito frequentemente usado de forma vaga, ambígua e equivocada. Apesar da imprecisão no seu uso, seja na imprensa, seja no discurso do dia a dia, a Organização das Nações Unidas para Educação, Ciência e Cultura (UNESCO, 2005) a define como o conjunto de traços característicos, espirituais, materiais e afetivos que caracterizam 
uma sociedade ou grupo social e que abrange, além das artes e das letras, os modos de vida, as maneiras de viver juntos, os sistemas de valores, as tradições e as crenças. É o que dá vida ao ser humano: seus costumes, festas, conhecimento, o território. Ela engloba, além das artes e das letras, os modos de vida, os direitos fundamentais do ser humano, os sistemas de valores, crenças e tradições. Sendo assim, "é a própria cultura que pode dar credibilidade de existência e identidade a um grupo de pessoas ou comunidade", atuando como fermento do desenvolvimento (CASTILHO; ARENHARDT; BOURLEGAT, 2009, p. 161-2). A cultura também é vista como um agente transformador. Como argumentam Kashimoto, Marinho e Russeff (2002, p. 35), a "cultura é um conjunto de soluções originais que um grupo de seres humanos inventa, a fim de se adaptar ao meio ambiente natural e social".

Dessa forma, a identidade cultural de uma comunidade ou grupo de pessoas define-se por diversos aspectos, entre eles, destacam-se: a língua, as relações sociais, ritos e cerimônias, costumes, sistemas de valores e crenças, como defendem Arnaudo e Corbella (2013). Como a ideia de cultura transcende fronteiras, não é suficiente trabalhar com a identidade cultural para se analisar a sustentabilidade ambiental de uma comunidade local.

Para Martins (2002, p. 54), "quando se fala de 'local', está-se referindo à escala das inter-relações pessoais da vida cotidiana, que sobre uma base territorial constroem sua identidade". Nesse contexto, o conceito de território torna-se imprescindível, sob pena de se cair num discurso vazio, desprovido de base empírica, inviabilizando trabalhar a sustentabilidade de uma comunidade de forma científica. Portanto compreende-se o território como o somatório dos sistemas naturais de um determinado país ou uma determinada área, com as realizações introduzidas pelos homens (CASTILHO; ARENHARDT; BOURLEGAT, 2009).

Considera-se que o território é o componente essencial da comunidade, de cuja vida social, econômica e política é matriz. Assim, para Castilho, Arenhardt e Bourlegat (2009, p. 163) “a territorialidade é o exercício de poder social, político e econômico em um contexto local ou nacional que resulta do processo de valorização do espaço geográfico". Para tanto, toda comunidade deve ter o controle do seu território; isto importa em definir a superfície que lhe corresponde, em estabelecer os seus limites. Para Raffestin (1993, p. 10) “[...] Falar de território é fazer uma referência implícita à noção de limite que, mesmo não sendo traçado, como em geral ocorre, exprime a relação que um grupo mantém com uma porção do espaço". As concepções que envolvem o território eleva-o à peça fundamental para a sustentabilidade ambiental, pois o uso adequado dos recursos naturais, tais como: flora, fauna, solo, água, entre outros, que formam parte do seu território, contribuirá sobremaneira para a sustentabilidade ambiental.

Quando se reporta ao desenvolvimento sustentável, nesse contexto, três dimensões revelam-se de suma importância: econômica, social e ambiental. O pressuposto básico está centrado na melhora da qualidade de vida dos indivíduos e na coletividade. Concebe-se como coletividade as comunidades locais, dentre elas as tradicionais, que se utilizam do território como base de sustentação da vida.

Nessa concepção, as principais características encontradas no conceito de comunidade, autores de diversas linhas de pensamentos, como Maclver e Page (1978), Tönnies (1978), Weber (1978), destacam a importância das relações sociais para o entendimento desse conceito. Assim, por exemplo, Tönnies (1978, p. 97) destaca que, em uma comunidade, "tudo que é confiante, íntimo, que vive exclusivamente junto, é compreendido como a vida em comunidade"; vida real, orgânica, em oposição à vida mecânica/virtual que caracterizam uma sociedade. 
Vale ressaltar que, para Weber (1978), as relações fundamentadas no sentimento subjetivo (afetivo, emotivo ou tradicional) dos partícipes indicam a presença de uma comunidade; se, ao contrário, as relações sociais estiverem baseadas em motivos racionais, com relação a fins e valores, estamos diante de uma sociedade. Weber (2004) formula ainda o conceito de grupos étnicos, que agregam características mais específicas de uma comunidade como as lembranças de colonização e migração, bem como a crença de uma procedência comum. Observa-se que a territorialidade não se constituía, entre os clássicos, um fator importante para a identidade de uma comunidade. A questão ambiental não era, na época, uma preocupação que envolvesse a sustentabilidade ambiental de uma comunidade.

Cabe considerar que, no caso dos povos indígenas no Brasil, a noção proposta por Weber para grupos étnicos se mostra pertinente para definir esses povos, porém insuficiente uma vez que as noções de território e territorialidade são fundamentais para caracterizar esses grupos.

Características apontadas por Maclver e Page (1978, p. 122) ressaltam que não importa o tamanho do grupo, mas que "vivam juntos e de modo tal que partilhem, não deste ou daquele interesse, mas das condições básicas de uma vida em comum, chamamos a esse grupo comunidade". Considera-se, também, que o princípio de pertença enaltece o sentimento de inclusão na comunidade, criando laços de identidade social e de solidariedade com o grupo. Esse fator, associado aos parâmetros de racionalidade (benefício/custo), aos códigos de conduta (padrões éticos e morais) conformam a lógica que fundamenta os princípios da ação humana.

Sendo assim, a relação entre identidade de uma comunidade e desenvolvimento local, requer que a identidade da comunidade, além dos seus componentes culturais, esteja centrada na identidade territorial, onde se encontra presente o sentimento de pertencimento que leva à participação e construção coletiva do processo de desenvolvimento local.

Desse modo, pode-se fazer a seguinte reflexão: que a Identidade Territorial (IT) dá origem a uma Solidariedade Social (SS) que leva à Participação Coletiva (PC) em favor da comunidade, possibilitando desencadear a construção de um processo de Desenvolvimento Local (DL), estabelecendo uma relação de causalidade entre esses componentes, como indicado no diagrama abaixo:

\section{$\mathrm{IT} \Rightarrow \mathrm{SS} \Rightarrow \mathrm{PC} \Rightarrow \mathrm{DL}$}

Considerando-se essa relação, o processo de Desenvolvimento Local (DL) corresponde a um processo de Construção de Território (CT), portanto pode-se sintetizar esta relação da seguinte forma:

\section{$\mathrm{DL}=\mathrm{CT}$}

Considera-se o desenvolvimento local como processo de transformação centrado no ser humano como proxy para a melhoria da qualidade de vida da coletividade, dos grupos sociais e das comunidades. Esse processo revela-se dinamizador da sociedade mediante novas formas de produzir, consumir e compartilhar. Baseado no social, no econômico e na base de sustentação material, isto é, em recursos naturais e tecnológicos que viabilizam a organização da produção e a organização social, o desenvolvimento local pode configurar-se como uma alternativa para as comunidades locais (tradicionais ou não), tornarem-se gestoras do seu desenvolvimento. 
Além das questões tratadas até aqui, nesta seção, incluindo-se a cultura, identidade, território e comunidade, considera-se indispensável levar em conta o conhecimento tradicional, pujante nas comunidades, como alicerce para a melhoria da qualidade de vida e sustentabilidade dessas comunidades. Natureza, cultura e produção são aspectos inseparáveis na construção dos saberes locais. Na literatura especializada, encontram-se referências a diversas tipologias de conhecimento, tais como: Conhecimento Local (CL); Conhecimento Ecológico Tradicional (CET); Conhecimento Indígena (Cl); Conhecimento dos Habitantes Rurais (CHR) e Conhecimento Comunitário (CC). Dessa forma, tanto o conhecimento científico quanto o conhecimento tradicional promovem e potencializam o desenvolvimento local.

Neste trabalho, o conceito de comunidade centra-se na análise de comunidades indígenas; especialmente, pretende-se focalizar os aspectos balizadores para o desenvolvimento local de tais comunidades, com base no conhecimento, saberes e fazeres dessas comunidades. Toma-se como base de informação uma revisão de trabalhos publicados com base na atividade turística e sua relação com as comunidades indígenas do Brasil, especificamente dos Pataxó no Sul da Bahia e os Potiguara, na Paraíba.

\section{TURISMO CULTURAL E O ETNOTURISMO NAS COMUNIDADES INDÍGENAS PATAXÓ, BA, E POTIGUARA, PB}

A contribuição deste artigo para o debate em torno do desenvolvimento local, especialmente envolvendo a atividade turística, permite incorporar as experiências vivenciadas pelas comunidades tradicionais. Para tanto, abordam-se os saberes e fazeres de duas comunidades indígenas do Brasil: os Pataxós, na Bahia, e os Potiguara, na Paraíba.

As comunidades indígenas que habitam o Brasil, por apresentarem cultura e tradições especiais, caracterizam-se como atrativos culturais para visitantes do país e do mundo, dando suporte a dois segmentos turísticos de destaque dentro desta atividade: O Turismo Cultural e o Etnoturismo.

O Turismo Cultural caracteriza-se como aquele em que os turistas procuram conhecer os bens materiais e imateriais produzidos pelas populações locais, bens esses que constituem o patrimônio cultural de uma localidade (FARIA, 2002). No Brasil, os visitantes atraídos têm interesses em conhecer os costumes e tradições seculares dessas comunidades tradicionais.

O Decreto Lei de n. 6.040/07 estabelece na legislação federal a definição de Povos e Comunidades Tradicionais como:

Grupos culturalmente diferenciados e que se reconhecem como tais, que possuem formas próprias de organização social, que ocupam e usam territórios e recursos naturais como condição para sua reprodução cultural, social, religiosa, ancestral e econômica, utilizando conhecimentos, inovações e práticas gerados e transmitidos pela tradição. (BRASIL, 2007b, p. 1).

Especificamente, para corroborar com a definição para os povos indígenas, apresenta-se a Convenção n. 169 sobre povos indígenas e tribais e Resolução referente à ação da Organização Internacional do Trabalho (OIT):

Povos em países independentes considerados indígenas pelo fato de descenderem de populações que viviam no país ou região geográfica na qual o país estava inserido no momento da sua conquista ou colonização ou do estabelecimento de suas fronteiras atuais e que, independente de sua condição jurídica, mantêm algumas de suas próprias instituições sociais, econômicas, culturais e políticas ou todas elas. (OIT, 2011, p. 15). 
A OIT (2011, p. 15) assevera que "[...] a autoidentificação como indígena ou tribal deverá ser considerada um critério fundamental para a definição dos grupos aos quais se aplicam as disposições da presente Convenção".

Para subsidiar essa reflexão, apresenta-se a comunidade indígena dos Pataxó Meridionais, que vivem na aldeia de Coroa Vermelha, em Santa Cruz de Cabrália, a 7 km de Porto Seguro, Bahia e a aldeia Potiguara de Tramataia, situada na Área de Proteção Ambiental (APA) da Barra do Rio Mamanguape, município de Marcação, a cerca de 70 km de João Pessoa, no Estado da Paraíba.

De acordo com Freitas e Mattos (2009) e Neves (2010), os Pataxó ocuparam, antes da colonização, a região que vai do norte de Minas Gerais até próximo ao litoral de Porto Seguro. Atualmente, habitam grande parte do litoral da Bahia, na região próximo a Porto Seguro, contabilizando 23 aldeias, além de algumas outras na região norte de Minas Gerais.

Os Pataxó da Coroa Vermelha, de acordo com Neves (2010, p. 93), “[...] se encontram engajados na exploração da atividade turística na região próxima a Porto Seguro, se aproveitando do fluxo turístico local, através do Projeto de Ecoturismo da Reserva Jaqueira".

Já a população da aldeia Potiguara de Tramataia, de acordo com Barbosa e Silva (2012), diferentemente dos Pataxó da Coroa Vermelha, não tem investido tanto na atividade turística pois as principais atividades desenvolvidas na localidade são: a pesca marinha, a agricultura e a criação de camarões em viveiro. Também se deve destacar o fato de que essa comunidade tem sido historicamente alvo de degradação ambiental, pela presença de atividades degradadoras como plantio de cana, que perdura até os dias atuais, apesar de ter sido nomeada como área de preservação ambiental desde 1993.

Como afirma Haesbaert (2007), para as populações tradicionais ou empobrecidas, o território é visto como abrigo, um conceito que vincula o sujeito ao ambiente no nível material, simbólico e social. Já para grupos modernos, o território pode ser visto como uma dentre várias possibilidades geográficas que, através da renda monetária, são passíveis de exploração e fruição econômica ou extraeconômica. Desse modo, Toledo (1996) considera que o uso dos recursos naturais, o controle cultural, a regulação dos controles econômicos exigem que a comunidade tome decisões que salvaguardem seus próprios valores culturais.

Os Pataxó, através de sua cultura, dos saberes e fazeres lançaram mão da confecção e venda de artesanato e, "foram se estabelecendo próximo aos dois municípios que estavam em plena fase de crescimento impulsionado pela atividade turística; e encontraram no turismo uma alternativa para seu sustento" (FREITAS; MATTOS, 2009, p. 120). Foi, a partir daí, que na visão dos autores, os índios Pataxó do Sul da Bahia, aos poucos foram se configurando como mais um atrativo turístico da região.

Quando se observa a tradição, logo vêm à tona os costumes que são passados de geração em geração ao longo da história de uma comunidade, povo, etnia ou nação. Nessa concepção, destaca-se o ritual do Awê que é considerado o único ritual tradicional entre os Pataxó Meridionais (FREITAS; MATTOS, 2009; NEVES, 2010). Para Toledo e Barrera-Bassols (2008, p. 108), compreender de maneira adequada "[...] o conhecimento tradicional é necessário então entender a própria natureza da sabedoria local, que é baseada (é formada) na completa inter-relação entre crenças, conhecimentos e de práticas".

Representação de cultura é, para os Pataxó, a exibição de suas tradições para um público externo à comunidade indígena, geralmente realizada mediante alguma espécie de troca com a parte que os contrata para a encenação, que, em muitas ocasiões, é ensaiada para o bom êxito. 
Apesar do fator econômico aí em questão, a tônica das representações está também em se fazer vistos, em se tornar visíveis como índios legítimos para o público que os assiste (GRÜNEWALD, 2003).

À luz das discussões sobre globalização versus localidade, destaca-se, conforme apontam Trevizan e Simões (2006, p. 9), que "[...] descobrir e dar vida às especificidades do local é uma forma de atrair o global para o local". A arte, o artesanato, os ritos, entre outros valores que permeiam as comunidades tradicionais constituem patrimônio cultural, que, por intermédio dos fazeres e saberes, se perpetuam ao longo do tempo. Dessa forma, na visão dos mesmos autores, quando o local encontra e assume sua identidade, potencializa-se no âmbito cultural, possibilitando o oferecimento de alternativas para o Turismo Cultural.

Já em relação aos Potiguara de Tramataia, Barbosa e Silva (2012) acreditam que o Etnoturismo seria uma alternativa bastante interessante não apenas em relação aos aspectos econômicos e ambientais, mas especialmente como forma de promover uma valorização da própria cultura "na medida em que a comunidade local tenderá a se preocupar com os acontecimentos, fatos históricos, culinária, artesanato, e seus mais antigos costumes" tendo em vista que tais aspectos têm sido relativamente desprezados.

De acordo com o Ministério do Turismo-Mtur, o etnoturismo pode ser considerado como: "um segmento turístico que é formado por atividades turísticas que buscam fazer com que os turistas vivenciem experiências autênticas em contatos diretos com os modos de vida e da identidade de grupos étnicos" (BRASIL, 2004, p. 17). Assim, essa modalidade turística poderia contribuir para o desenvolvimento local da referida comunidade indígena, tanto para a preservação ambiental do território Tramataia e quanto para sua respectiva valorização cultural.

Os povos tradicionais com o referencial da conservação da natureza, do uso sustentável dos recursos naturais, com a consequente prestação de serviços ambientais, a partir de um reconhecimento mútuo se caracterizam pela dependência e até simbiose com a natureza; na elaboração de estratégias de uso e de manejo dos recursos naturais; na noção de território ou espaço onde se reproduz econômica e socialmente e, em especial, como foco da análise realizada neste estudo; na importância das simbologias, mitos e rituais (PRADO, 2012).

Os casos dos Índios Pataxó, no Sul da Bahia, e Potiguara de Tramataia, na Paraíba, não se configuram como os únicos, levando-se em conta que o território brasileiro é composto por inúmeras etnias indígenas. Sendo que cada uma delas pode se configurar como única a partir de sua identidade, territorialidade e cultura, em que prevalece o conhecimento tradicional. Portanto o desenvolvimento local deve ser potencializado observando-se essas comunidades e permitindo-se o pleno exercício de sua autonomia sobre os seus territórios.

\section{CONSIDERAÇÕES FINAIS}

Infere-se, das reflexões aqui desenvolvidas, que o desenvolvimento é um processo que pressupõe transformações econômicas e sociais de comunidades. O objetivo principal deste artigo foi ampliar a discussão sobre a relação entre os conceitos de desenvolvimento local, turismo e populações tradicionais. Especificamente, no caso do desenvolvimento local, verificou-se ser necessário dotá-lo de um caráter mais humano, permitindo que os indivíduos, partícipes das comunidades, tornem-se protagonistas importantes no processo de desenvolvimento, elevando a qualidade de vida da comunidade, superando-se como problema básico o acesso à educação, saúde e a segurança alimentar. 
Considerando-se que a cultura e a identidade precedem a qualquer dinâmica de desenvolvimento local, para as comunidades tradicionais e, neste caso, os povos indígenas, a arte, o artesanato, os ritos, entre outros valores que permeiam essas comunidades constituem patrimônio cultural, que, por intermédio dos fazeres e saberes, se perpetuam ao longo do tempo. Dessa forma, o local, quando encontra e assume a sua identidade, potencializa-se como alternativa ao Turismo Sustentável, em especial, ao Turismo Cultural e ao Etnoturismo, contribuindo tanto para a preservação ambiental do território quanto a sua respectiva valorização cultural. Ademais, verificou-se que o turismo, se bem planejado, pode gerar impactos positivos, como a afirmação da identidade cultural das comunidades indígenas.

\section{REFERÊNCIAS}

ARAÚJO, W. A. de. Desenvolvimento econômico e arranjo produtivo local: uma relação necessária. São Mateus, ES: Opção, 2010.

ARCHER, B.; COOPER, C. Os impactos positivos e negativos do turismo. In: THEOBALD, W. F. (Org.). Turismo global. 2. ed. São Paulo: SENAC, 2002.

ARNAUDO, M. F.; CORBELLA, V. Análisis de la potencialidad de Monte Hermoso para lograr el desarrollo local a partir de bienes culturales. Revista de Investigación en Turismo y Desarrollo Local, Málaga, Espanha, v. 6, n. 15, p. 1-11, dez. 2013.

BACAL, S. S.; MIRANDA, S. M. de A. Impacto do turismo nos núcleos receptores: necessidade de normalização. São Paulo: Hucitec, 1997.

BARBOSA, I. K. P.; SILVA, C. B. C. da. Ecoturismo e etnoturismo na aldeia de Tramataia- área de proteção ambiental da barra de Mamanguape-PB: uma nova alternativa econômica sustentável ou mais um fator gerador de conflitos sócio-ambientais? Âmbito Jurídico, Rio Grande, XV, n. 98, mar. 2012. Disponível em: <http://www.ambitojuridico.com.br/site.php?n-link=revista_artigos-leitura\&artigo-id=11279>. Acesso em: fev. 2015.

BIGNÉ, E.; FONT, X.; ANDREU, L. Marketing de destinos turísticos: análisisy estrategias de desarrollo. Madri: ESIC, 2000.

BRASIL. Ministério do Turismo (Mtur). Turismo e sustentabilidade, formação de redes e ação municipal para regionalização do turismo. Brasília: MTUR; Florianópolis: SEAD/UFSC, 2010.

. Ministério do Turismo (Mtur). Coordenação Geral de Regionalização. Turismo e sustentabilidade. Roteiros do Brasil - programa de regionalização do turismo. Brasília: MTUR, 2007a. 126p.

Decreto Lei n. 6.040, de 7 de fevereiro de 2007. Institui a Política Nacional de Desenvolvimento Sustentável dos Povos e Comunidades Tradicionais. Diário Oficial [da] República Federativa do Brasil, Brasília, DF, Poder Executivo, 8 jul. 2007b.

Ministério do Turismo (Mtur). Segmentação do turismo: marcos conceituais. Programa de Regionalização do turismo. Brasília: Ministério do Turismo, 2004.

CASTILHO, M. A. de; ARENHARDT, M. M.; LE BOURLEGAT, C. A. Cultura e identidade: os desafios para o desenvolvimento local no assentamento Aroeira, Chapadão do Sul, MS. Interações: Revista Internacional de Desenvolvimento Local, v. 10, n. 2, p. 159-69, jul./dez. 2009.

CORIOLANO, L. N. M. T. O desenvolvimento voltado às condições humanas e o turismo comunitário. In: CORIOLANO, L. N. M. T.; CRUZ, L. L. (Org.). Turismo comunitário e responsabilidade socioambiental. Fortaleza, CE: EDUECE, 2003.

DIAS, R. Turismo sustentável e meio ambiente. São Paulo: Atlas, 2008.

ESPÍNOLA, R.; ANDRADE, M. Turismo em comunidades tradicionais: dilemas e perspectivas no município de Conde-PB. In: GONÇALVES, A.; RODRIGUES, L. (Org.). Políticas de turismo, ambiente e desenvolvimento. João Pessoa, PB: Ed. UFPB, 2015. (Vol. 3, Série Pesquisa Prodema). 
FARIA, I. F. Ecoturismo: etnodesenvolvimento e inclusão social no Amazonas. Manaus: Ed. UFAM, 2002.

FARIA, M. C. P. Análisis de la capacidade del turismo em el desarrollo econômico regional: el caso de Inhotim y Brumadinho. 2012. 234p. Tese (Doutorado em Economia) - Universidad de Alicante, Espanha, 2012.

FREITAS, T. P.; MATTOS, Y. Impactos culturais do turismo: contradições e paradoxos - estudo de caso com os Índios Pataxó de Porto Seguro e Santa Cruz de Cabrália BA. Revista Eletrônica de Turismo Cultural, v. 3, n. 1, p. 117-23, 2009. Disponível em: <http://www.eca.usp.br/turismocultural/05_\%C3\%8Dndios_ Patax\%C3\%B3s_Tatiana.pdf>. Acesso em: dez. 2013.

GRÜNEWALD, R. A. Etnodesenvolvimento indígena no Nordeste (e Leste): aspectos gerais e específicos. Revista Anthropológicas, ano 7, v. 14, n. 1-2, p. 47-71, 2003.

HAESBAERT, R. Território e multerritorialidade: um debate. Revista GEOgraphia, ano IX, n. 17, p. 19-46, 2007.

INSTITUTO DE HOSPITALIDADE (IH). NIH-54. Certificação em turismo sustentável: norma nacional para meios de hospedagem - requisitos para a sustentabilidade. São Paulo: Conselho Nacional da Reserva da Biosfera da Mata Atlântica, 2005.

KASHIMOTO, E. M.; MARINHO, M.; RUSSEFF, I. Cultura, identidade e desenvolvimento local: conceitos e perspectivas para regiões em desenvolvimento. Interações: Revista Internacional de Desenvolvimento Local, Campo Grande, MS, v. 3, n. 4, p. 35-42, mar. 2002.

LAGE, B. H. G.; MILONE, P. C. Economia do turismo. 7. ed. São Paulo: Atlas, 2001.

LOZADA, L. Serviços ecossistêmicos e interações com uma comunidade afrodescendente no Pacífico colombiano: dos riscos à proteção da biodiversidade. 2017. Dissertação (Mestrado em Desenvolvimento e Meio Ambiente)- Universidade Federal da Paraíba, João Pessoa, PB, 2017.

MACIVER, R. M.; PAGE, C. H. Comunidade e sociedade como níveis de organização da vida social. In: FERNANDES, F. Comunidade e sociedade: leituras sobre problemas conceituais, metodológicos e de aplicação. São Paulo: Nacional/EDUSP, 1978.

MARTINELLI, D. P.; JOYAL, A. Desenvolvimento local e o papel das pequenas e médias empresas. Barueri, SP: Manole, 2004.

MARTínEZ, H. J.; VILLA, M. A.; VÁZQUEZ, A. E. G. Bienestar socioeconómico y percepción de la calidad de vida en destinos turísticos: el caso de la Colina el Caribe, Cabo San Lucas, Baja California Sur (México). Revista de Investigación en Turismo y Desarrollo Local, Málaga, Espanha, v. 6, n. 15, p. 1-16, dez. 2013.

MARTINS, S. R. O. Desenvolvimento local: questões conceituais e metodológicas. Interações: Revista Internacional de Desenvolvimento Local, Campo Grande, MS, v. 3, n. 5, p. 51-9, set. 2002.

NEVES, S. C. Eficácia ritual e eficácia turística: o ritual do Awê entre os Pataxó Meridionais e o turismo. Cultur: Revista de Cultura e Turismo, ano 4, n. 2, p. 92-103, jun. 2010. Disponível em: <www.uesc.br/ revistas/cultureturismo>. Acesso em: dez. 2013.

ORGANIZAÇÃO DAS NAÇÕES UNIDAS PARA EDUCAÇÃO, CIÊNCIA E CULTURA (UNESCO). Convención sobre la protección y promoción de la diversidad de las expresiones culturales. 2005. Disponível em: <http:// portal.unesco.org/es/ev.phpURL>. Acesso em: 30 ago. 2013.

ORGANIZAÇÃO INTERNACIONAL DO TRABALHO (OIT). Convenção n. 169 sobre povos indígenas e tribais e Resolução referente à ação da OIT. Brasília: OIT, 2011. 1 v.

ORGANIZAÇÃO MUNDIAL DO TURISMO (OMT). Crónicas del turismo: el desarrollo comunitario sobre el terreno. 2014. Disponível em: <http://wtd.unwto.org/es/content/tourism-stories-communitydevelopment-ground>. Acesso em: 1ำ jun. 2015.

PRADO, R. M. Viagem pelo conceito de populações tradicionais, com aspas. In: STEIL, C. A.; CARVALHO, I. C. M. (Org.). Cultura, percepções e ambiente: diálogo com Tim Ingold. São Paulo: Terceiro Nome, 2012.

RAFFESTIN, C. Por uma geografia do poder. Tradução de Maria Cecília França. São Paulo: Ática, 1993. 
SARAIVA, L. A. S. Métodos narrativos de pesquisa: uma aproximação. Gestão.Org, v. 5, n. 2, p. 118-34, maio/ ago. 2007. Disponível em: < https://periodicos.ufpe.br/revistas/gestaoorg/article/view/21604/18298>. Acesso em: 20 maio 2017.

SEN, A. Desenvolvimento como liberdade. São Paulo: Companhia das Letras, 2010.

SOUZA, N. de J. de. Desenvolvimento econômico. 5. ed. rev. São Paulo: Atlas, 2005.

SWARBROOKE, J. Turismo sustentável: conceitos e impacto ambiental. São Paulo: ALEPH, 2000.

TOLEDO, V. M. Principios etnoecológicos para el desarrollo sustentable de comunidades campesinas e indígenas. Reproduzido com modificações do artigo publicado em CLAVES, Temas Clave, n. 4, ago. 1996.

TOLEDO, V. M.; BARRERA-BASSOLS, N. La memoria biocultural: la importância ecológica de las sabidurías tradicionales. Barcelona, Espanha: Icaria, 2008.

TÖNNIES, F. Comunidade e sociedade como entidades típico-ideais. In: FERNANDES, F. Comunidade e sociedade: leituras sobre problemas conceituais, metodológicos e de aplicação. São Paulo: Nacional/ EDUSP, 1978.

TREVIZAN, S. D. P.; SIMÕES, M. de L. N. Global e local: conflito ou complementaridade. In: TREVIZAN, S. D. P.; SIMÕES, M. de L. N. (Org.). Comunidades sustentáveis: a partir do turismo com base local. Ilhéus, BA: Editus, 2006.

VERGARA, S. C. Projetos e relatórios de pesquisa em administração. 4. ed. São Paulo: Atlas, 2003.

WEBER, M. Economia e sociedade. São Paulo: Imprensa Oficial de São Paulo, 2004.

Comunidade e sociedade como estruturas de socialização. In: FERNANDES, F. Comunidade e sociedade: leituras sobre problemas conceituais, metodológicos e de aplicação. São Paulo: Nacional/ EDUSP, 1978.

\section{Sobre os autores:}

Wilson Alves de Araújo: Doutorando em Desenvolvimento e Meio Ambiente (PRODEMA/UESC). Mestre em Economia Empresarial pela Universidade Cândido Mendes (UCAM/RJ). Professor Assistente da Universidade do Estado da Bahia- UNEB, Departamento de Ciências Humanas e Tecnologias (DCHT), Campus Eunápolis. Membro do Grupo de Pesquisa "Memória, Espaço e Linguagem" (UNEB), com atuação na Linha de pesquisa: Políticas Públicas, Cultura e Turismo.

E-mail:wilsonaaraujo@gmail.com

Joelma Abrantes Guedes Temoteo: Doutoranda em Desenvolvimento e Meio Ambiente (PRODEMA/UFPB). Mestre em Desenvolvimento e Meio Ambiente (PRODEMA/UFPB). Professora Assistente da Universidade Federal da Paraíba (UFPB) - Departamento de Turismo e Hotelaria. E-mail: joelma.abrantes@gmail.com

Maristela Oliveira de Andrade: Doutora em TroisiemeCycle - IHEAL - Universite de Paris III (Sorbonne-Nouvelle). Professora do Doutorado em Desenvolvimento e Meio Ambiente (PRODEMA/UFPB). Professora Titular da Universidade Federal da Paraíba (UFPB)- Departamento de Ciências Sociais. E-mail: andrademaristela@hotmail.com

Salvador Dal Pozzo Trevizan: Ph.D. em Sociologia, University of Wisconsin-Madison, USA. Professor do Doutorado em Desenvolvimento e Meio Ambiente (PRODEMA/UESC) Professor Pleno do Departamento de Ciências Agrárias e Ambientais, da Universidade Estadual de Santa Cruz, UESC, BA. E-mail: salvador@uesc.br 